\title{
An Investigation of Geomechanical and Microstructural Properties of Full-Scale Jet Grout Column Constructed in Organic Soil
}

\author{
Mustafa Fahmi Hasan ${ }^{1} \cdot$ Hanifi Canakci ${ }^{2,3}$ (1)
}

Received: 14 March 2021 / Accepted: 5 September 2021

(c) King Fahd University of Petroleum \& Minerals 2021

\begin{abstract}
Jet grouting methods have recently become one of the soil enhancement technologies utilized to provide strength improvement and solve most problems of weak soils. In this study, a full-scale $1 \mathrm{~m}$ diameter and $5 \mathrm{~m}$ length jet grout (soilcrete) column was constructed in the field with a water-to-cement ratio of 1 and 400 bar pressure injections. A mechanical, physical, and microstructural investigation was performed on jet grout samples taken from six different depths $(0.0,0.5,1.0,1.5,2.0$, and $2.5 \mathrm{~m}$ ) and at the same depth at five different locations, including the center. For normal conditions, samples were prepared for six periods to study dry and saturated conditions. The following tests are performed on each sample: compressive strength index $\left(I_{S}\right)$ in all conditions, water absorption, density, porosity, and interface friction. Additionally, SEM was performed on selected samples to investigate the microstructures of jet grout columns (JGCs). The test results showed that the $\mathrm{I}_{\mathrm{s}}$ varies with depth, and within the same depth, the variation is approximately $20 \%$. Other properties also vary with depth and location; for example, the average percentage of water absorption and porosity are considered minimum values at the same location, which are 53 and $30 \%$, respectively. However, the interface friction angle of organic soil-cement grout gains $48^{\circ}$ and $10 \mathrm{kPa}$ cohesion. The theoretical part of this study is to predict the diameter of JGC in organic soil.
\end{abstract}

Keywords Jet grout column, Organic soil $\cdot$ Compressive strength index $\cdot$ Physical characteristic $\cdot$ Interface friction $\cdot$ SEM studies · Diameter studies

\section{List of symbols}

JGC Jet grout column

PC Portland cement

USCS Unified soil classification system

Is Compressive strength index

D Porosity

$\rho \quad$ Density

$\tau \quad$ Shear stress

$\sigma \quad$ Normal stress

$\Phi \quad$ Internal friction angle

c Cohesion

\section{Hanifi Canakci}

canakci@gantep.edu.tr

1 Department of Civil Engineering, Erbil Polytechnic University, 44001 Erbil, Iraq

2 Department of Civil Engineering, Hasan Kalyoncu University, 27410 Gaziantep, Turkey

3 Department of Civil Engineering, Gaziantep University, 27310 Gaziantep, Turkey

\section{SEM Scanning electron microscopy}

\section{Introduction}

The jet grouting method has been an effective method used in solving many geotechnical problems. The diversity in jet grout systems allows users to apply different production parameters to perform design criteria [1]. Croce et al. [2] presented that a grout mixture is injected from nozzles underground with high pressure at high velocity to press a soil surface and construct a soilcrete column. Continuously, this technique has the potential to be utilized in different applications with different types of soil, such as enhancing the bearing capacity [3], increasing the permeability in gravelly soil, reducing settlement in soft clayey soil, and resisting liquefaction in sandy soil [4]. The main experiment facing the jet grouting method is accurate quality control of the soilcrete column [5]. Additionally, Tinoco et al. (2014) [6] reported beneficial improvements, such as quantity and economic effects, on the different parameters included in the 
jet grout (JG) process. Additionally, cost-effective and noninvasive geophysical measurements have been issued and used to extensive stock data that have to be integrated with direct investigations [7]. The compressive strength of each column should be checked through the soil development process [8, 9] because Erkan and Tan (2017) [10] concluded that the lifting speed and grout pressure widely influenced the performance of jet grouting columns (JGC). Generally, there are two major approaches for quality control of JGC construction, such as geometric dimensions and control of compressive strength of soilcrete columns [11]. When realized with the same jetting energy, the double-fluid system is more influenced than the monofluid system. Moreover, thanks to their aptitude to reduce the number of operations, the construction speed also improved with the double- and triple-fluid systems. Therefore, these systems are more indicated for the cases of mass treatment where the overlapping of grouted columns is prevalent [12].

The main construction problem related to the structure of soft soils such as organic soil is large compressibility and low bearing capacity. In particular, a high water content and low shear strength occur in organic soil exceptionally because of the low dry density. Therefore, construction built on organic soil deposits may cause excessive settlement and bearing capacity failure. Because of the low bearing capacity and hence the low shear strength, a surface foundation must be improved before construction works can begin. A suitable solution could be thought of as replacing the poor soil with suitable soil for filling. However, this application may be very expensive. In addition, waste excavated soil can be removed within an economically acceptable haul distance [13]. This method also needs maintenance work with respect to horizontal removal and long-term consolidation [14]. Organic deposits are commonly encountered around the world. For other "problem" soils, the behavior of organic soils often does not follow traditional rules of soil behavior, thus posing significant challenges to the design profession. The unsatisfactory strength characteristics associated with the low values of the maximum dry density are the main concern in road construction [15].

Güllü et al. (2016) and Ho et al. (2017) determined the soilcrete column mechanisms and compressive strength in different soil types. In addition, additive materials were utilized to develop the strength approach, and the effects of factors such as the density of soil, chemical reactions, curing time, and cement type on the strength of soil were initially observed under laboratory conditions utilizing strength tests such as unconfined compression tests $[16,17]$. A few researchers have reported that the compressive strength of full-dimension conditions is much lower than that of remolded conditions in the laboratory. It is clear that simulations of the prevailing unknowns and real construction conditions are not available in the laboratory. Even though laboratory research is a com-
Table 1 Organic soil engineering properties

\begin{tabular}{ll}
\hline Engineering properties & Result \\
\hline Organic content & $13 \%$ \\
Maximum dry density & $10.92 \mathrm{kN} / \mathrm{m}^{3}$ \\
Optimum water content & $56 \%$ \\
Natural water content & $154.832 \%$ \\
Fine sand & $30.67 \%$ \\
Clay and silt & $60.48 \%$ \\
Specific gravity & 2.052 \\
\hline
\end{tabular}

mon way to predict the microstructural parameters effecting the strength of soilcrete specimens, an examination of this consideration of the technical literature is not the focus of the present study. For the accurate study, for quality control of the geometry of jet grouting columns, research must focus on the columns' full-dimension sector to systematically simulate construction conditions [2]-[4]. The compressive strength values are found to be better due to the presence of $3 \%$ glass powder at the 28-day curing time for all clay contents. At the remaining curing times ( 7 and 14 days), the strength values mostly improved with the increased addition of glass powder.

Canakci et al. (2016) [18] and Uesugi and Kishida (1986) [19] reported that there are many influencing factors on the value of the interface friction angle, such as grain size, gradation, mineralogical composition, and density, as well as the roughness of the material surface. An intensive investigation was carried out to determine the interface friction between organic soil and concrete, smooth and rough steel, and wood, selected as structural materials. Test results showed that the highest interface friction angle was obtained between the organic soil and the concrete and that this was higher than that of other construction materials regardless of the shape of the soil particles $[18,19]$. The variation in density was affected according to the quantity and type of binder. Comparing the two soil mixes showed that the mix density with a higher percentage of kaolinite was lower than the other density [20, 21].

Carnevale et al. [22], Coelho et al. (2012) [23], Thiyyakkandi et al. [24], and Flora et al. (2013) [25] presented that the diameter and length of the soil-cement columns were considered the main significant factors in the geometry of the column, which is related to design predictions. The control length of the soil-cement column is not important to investigate because the drilling rods can be measured. Accordingly, the estimation and measurement of column diameter were considered a major challenge in jet grouting techniques; therefore, these studies have predicted the methods and mechanisms of estimating column diameter and the parameters that effect diameter size [26]. Recently, mathematical models have been used to solve quantitative 
Fig. 1 Particles size distribution of organic soil for present study

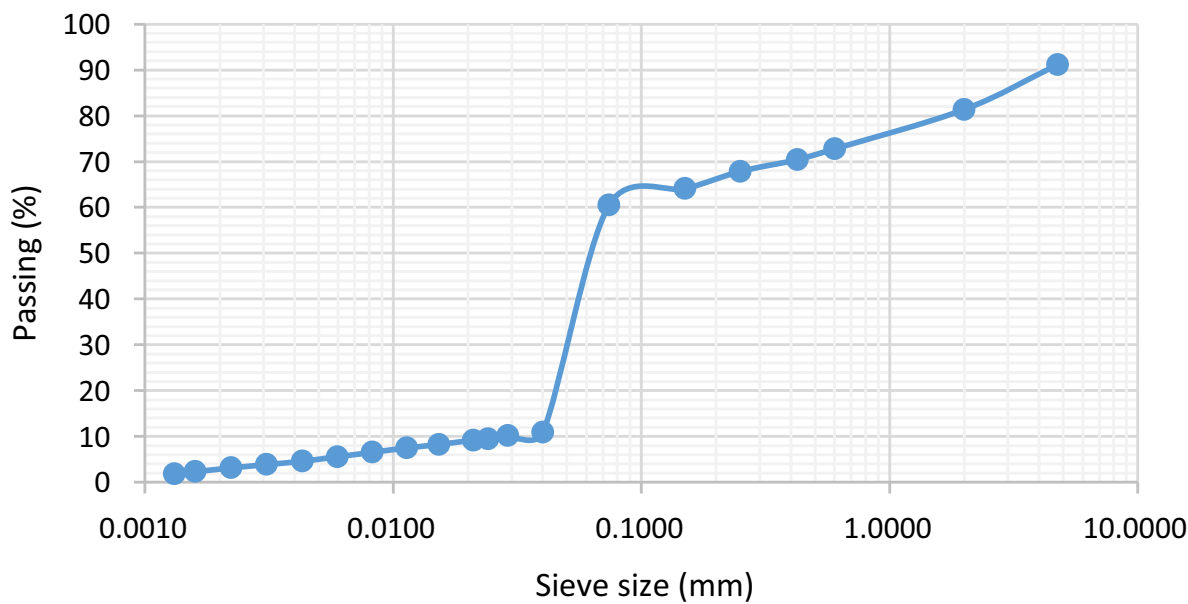

problems in engineering sectors due to deterministic form methods. On the other hand, finite element software studies the surface interface friction between the wall and jet grout slab [27]. Soil classification is considered a main part of any construction project, and geotechnical engineers need to learn before embarking on any construction project. All doubts happen because of the dynamic nature of the problem. This proposed fuzzy knowledge-based model has shown how fuzzy logic, as an expert system, can be implemented to determine the soil type and its proportionality in airfield applications. The pliability of this method empowers the rule validation identified in the system, which can be applied in the MATLAB programming environment. In addition, the advantage of the fuzzy knowledge-based model was considered as a quick and accurate tool to predict the soil type with one model trained and its rating for proportionality in airfield applications without the need to implement any manual work, such as utilizing charts or tables [28]. Recently, the trend of the current literature on pore-scale modeling has been to apply established simulation techniques or compare their performances. Therefore, the Bayesian network results proposed complete permeability in a microstructure to be influenced by a few parameters among the database of micronetwork entries [29]. As a software program, Kaur et al. (2021) [30] concluded that the reasonable application of finite element method-based analytical software tools such as Plaxis 3D to analyze the behavior of single and group piles embedded in two-layered soil consisting of an upper soft clay layer with a water content equal to the liquid limit overlying a dense sand layer with $80 \%$ relative density. It is concluded that an increase in the clay layer thickness has a detrimental effect on the lateral load resistance of piles. This causes a larger decrease in the lateral capacity of group piles [30].

Previous studies have shown that organic soil is classified as the weakest soil due to its high compressibility and low shear strength, and previous studies have presented different techniques to improve organic properties. Recently,
Table 2 Classification of organic soil according to ASTM

\begin{tabular}{|c|c|c|c|}
\hline $\begin{array}{l}\text { ASTM } \\
\text { standard }\end{array}$ & Criteria & Designation & Present study \\
\hline \multirow[t]{3}{*}{$\begin{array}{l}\text { Fiber content } \\
\text { (D1997) [54] }\end{array}$} & $\begin{array}{l}\text { Fibric } \\
\text { (H1-H3) }\end{array}$ & $>67 \%$ fibers & \multirow[t]{3}{*}{$\begin{array}{l}\text { Sapric } \\
(\mathrm{H} 7-\mathrm{H} 10)\end{array}$} \\
\hline & $\begin{array}{l}\text { Hemic } \\
\qquad(\mathrm{H} 4-\mathrm{H} 7)\end{array}$ & $33-67 \%$ fibers & \\
\hline & $\begin{array}{l}\text { Sapric } \\
(\text { H7-10) }\end{array}$ & $<33 \%$ fiber & \\
\hline \multirow{3}{*}{$\begin{array}{l}\text { Ash content } \\
\text { (D2974) [31] }\end{array}$} & Low ash & $<5 \%$ ash & \multirow{3}{*}{$\begin{array}{l}87 \% \\
\text { High ash }\end{array}$} \\
\hline & Medium ash & $5-15 \%$ ash & \\
\hline & High ash & $>15 \%$ ash & \\
\hline \multirow{4}{*}{$\begin{array}{l}\text { Acidity } \\
\text { (D2976) [55] }\end{array}$} & Highly acidic & $\mathrm{PH}<4.5$ & \multirow{4}{*}{$\begin{array}{l}\mathrm{PH}=5.11 \\
\text { Moderately } \\
\text { acidic }\end{array}$} \\
\hline & $\begin{array}{l}\text { Moderately } \\
\text { acidic }\end{array}$ & $4.5<\mathrm{PH}<5.5$ & \\
\hline & Slightly acidic & $5.5<\mathrm{PH}<7$ & \\
\hline & Basic & $\mathrm{PH}>7$ & \\
\hline
\end{tabular}

the jet grouting method has been noted as the most common technique to improve soil properties. However, all efforts to date have lacked data for enhancing organic soil by jet grouting techniques. In addition, no attempt has been made to investigate the geotechnical engineering properties of jet grout columns. In view of this, the present study observed the geomechanical properties of full-scale JGC in organic soil under different conditions (normal, dry, and saturated) according to directions and depth parameters. In this study, a full-scale JGC with a diameter of $1 \mathrm{~m}$ and length of $5 \mathrm{~m}$ was constructed in the field with a water-to-cement ratio of 1 and 400 bar pressure to investigate the mechanical properties (compression index and direct shear test) and physical properties (water absorption, porosity, and density test). Full-scale JGC was examined by SEM to observe the microstructural analysis of specimens according to directions and depth parameters. Finally, this paper presents extensive efforts of 


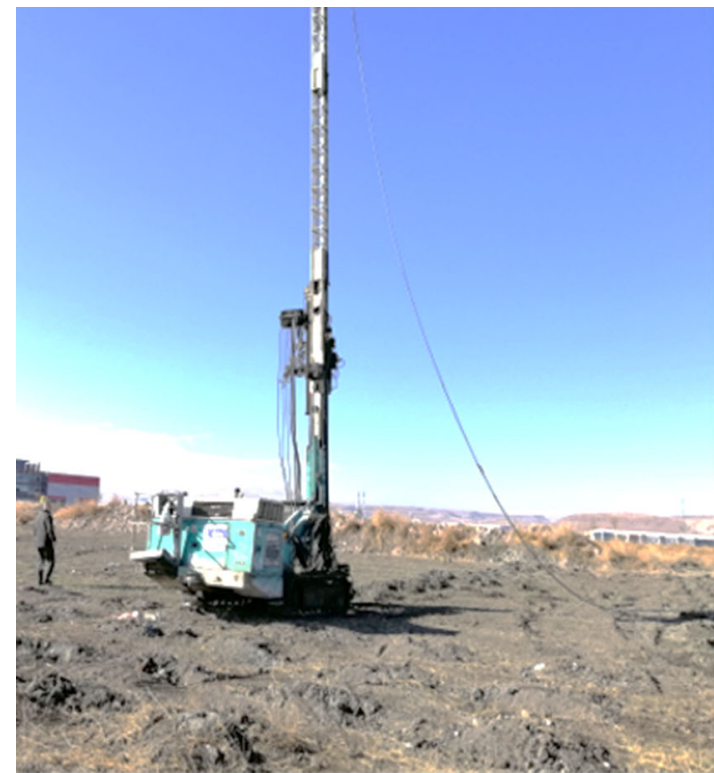

(a)

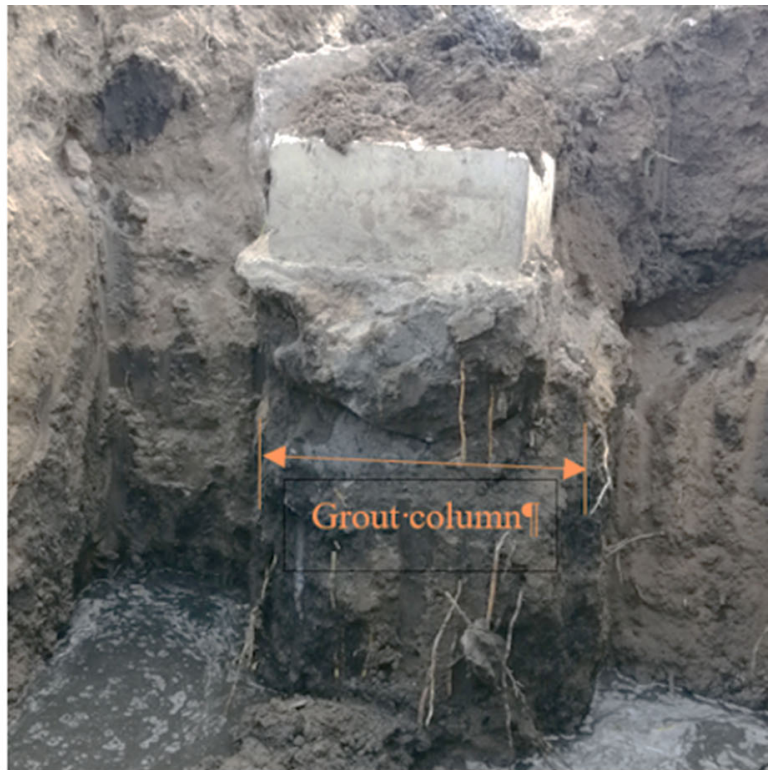

(b)

Fig. 2 Jet grouting column; a jet grouting machine; b full-scale grouting column

Table 3 Chemical and physical properties of CEM I $42.5 \mathrm{R}$ cement

\begin{tabular}{cll}
\hline Properties & Composition & Average value \\
\hline Chemical & $\mathrm{CaO}$ & 67.46 \\
& $\mathrm{SiO}_{2}$ & 13.48 \\
& $\mathrm{Al}_{2} \mathrm{O}_{3}$ & 3.69 \\
& $\mathrm{Fe}_{2} \mathrm{O}_{3}$ & 7.78 \\
& $\mathrm{MgO}$ & 1.29 \\
& $\mathrm{Na}_{2} \mathrm{O}$ & 0.36 \\
& $\mathrm{~K}_{2} \mathrm{O}$ & 0.98 \\
& $\mathrm{SO}_{3}$ & 4.82 \\
Physical & Specific weight $\left(\mathrm{g} / \mathrm{cm}^{3}\right)$ & 3.18 \\
& Specific surface area $($ Blaine $)\left(\mathrm{cm}^{2} / \mathrm{g}\right)$ & 3352 \\
& Loss on ignition $(\%)$ & 1.98 \\
\hline
\end{tabular}

JGC, and therefore any conclusion obtained in this study can be deemed useful for experiments.

\section{Material and Sampling}

\subsection{Organic soil}

The organic soil used in this study was obtained from Kayseri, Turkey. The organic soil samples were tested in the soil mechanics laboratory of the civil engineering department at Gaziantep University to determine physical and chemical properties related to the organic soil used. This organic soil is classified as $(\mathrm{OH})$ sandy organic silt by the Unified
Soil Classification System (USCS), as detailed in Table 1. In addition, the classification system, according to Wüst et al. (2003), is mineral soil or sediment with organic soil. Organic content was estimated by firing at $440{ }^{\circ} \mathrm{C}$ in an oven for 4 hours according to ASTM D 2974 [31]. Therefore, the ash content of the soil was defined as $87 \%$, and the organic content was $13 \%$. In addition, the particle grain size distribution curve of the sand is given in Fig. 1. The liquid limit of the organic soil was estimated by the fall cone test according to ASTM D 4318 [32] and found to be $142 \%$. According to ASTM standards, the soil classification system is given in Table 2.

\subsection{Jet Grouting Column (JGC)}

The technology "jet grouting" is an injection under high pressure of various chemical reagents - binders (strengtheners) - which serve to improve the properties of the soil. In this study, the JGC was constructed in Kayseri Region-Turkey at $38^{\circ} 44^{\prime} 58.179^{\prime \prime} \mathrm{N}$ and $35^{\circ} 21^{\prime} 4.099^{\prime \prime} \mathrm{E}$. The organic soil layer is approximately $7 \mathrm{~m}$ deep, and the full-scale dimension of the JGC is approximately $1 \mathrm{~m}$ in diameter and $5 \mathrm{~m}$ deep, as shown in Fig. 2a and b. In addition, after the drilling step, the injection process starts to construct the grout column by using the C6-Casagrande machine. Next, cement paste was prepared in the grout mixer using Portland cement (PC)-type CEM I-42.5R according to ASTM C150 [33], and the chemical and physical properties of PC are presented in Table 3. Therefore, the water-to-cement ratio was used to prepare the grout mix, and the rheological properties of grout were obtained from grout mixtures at various shear rates by using 
Fig. 3 Rheological properties of jet gout column: a Shear stress versus shear rate relationship; b coaxial rotating cylinder Rheometer

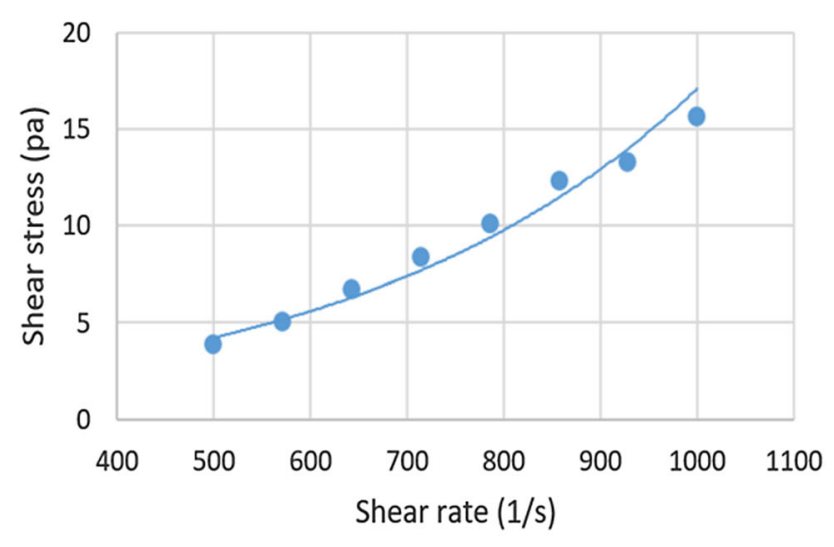

(a)

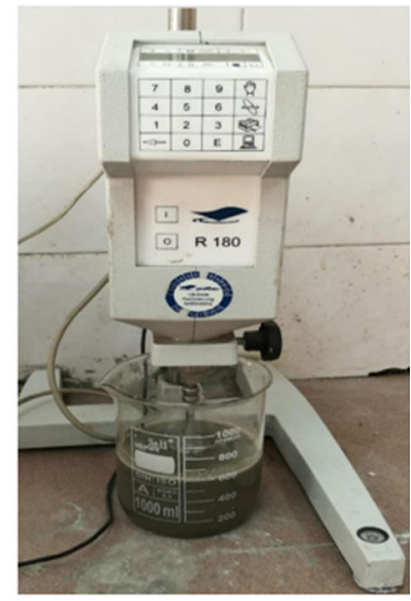

(b)
Table 4 Jet grouting column information

\begin{tabular}{ll}
\hline Materials & Properties \\
\hline Machine name & C6-Casagrande \\
Rotation & $18 \mathrm{r} / \mathrm{min}$ \\
Pullout speed & $85 \mathrm{~cm} / \mathrm{min}$ \\
Pressure & $400 \mathrm{bar}$ \\
Cement type & Cem I, 42.5 R \\
W/C & $1: 1$ \\
Viscosity (ASTM C393) & $33 \mathrm{~s} / 1000 \mathrm{ml}$ \\
Fluidity of concrete & $70 \%$ \\
\hline
\end{tabular}

a coaxial rotating cylinder rheometer (ProRheo R180 Instrument, Germany), as shown in Fig. 3a and b. Then, grout paste was injected with a constant pressure of 400 bar in the organic soil utilizing a pullout speed of $85 \mathrm{~cm} / \mathrm{min}$, as reported in Table 4, to construct the full-scale dimension of JGC. In this method, two different nozzles were placed opposite each other in the same rod, and from each nozzle, grout past and air with high pressure were injected to erode the soil and replaced with grout past to form the JGC after hardening. Figure 4 presents a schematic diagram of the soilcrete column formation procedures.

\subsection{Material Sampling}

This section covers the preparation of the test specimen after casting a full-scale grouting column in organic soil. Next, the grouting column was cured in organic soil for 28 days. After that, the area around the column was excavated to extract full-scale dimensions and transported to the geotechnical laboratory of Gaziantep University, Turkey, to prepare test specimens and analyze the $\mathrm{I}_{\mathrm{s}}$ and diameter with the general properties of the grout column. This paper examines grout columns under different conditions, such as normal, dry, and saturated conditions. For normal conditions, the test samples are labeled according to trends for each layer, which is from the center to the right, left, up, and down, and labeled according to depths from ground surface such as $0,0.5,1.0,1.5,2.0$, and $2.5 \mathrm{~m}$, as shown in Fig. $5 \mathrm{a}-\mathrm{c}$, respectively. Therefore, the sample labeled with "S0.0-C" denotes a sample test located in the center of the column at $0.0 \mathrm{~m}$ depth, and the others were named as shown in Table 5. Hence, a total of six samples at one layer were designed, and three samples at each location were used for work accuracy. A total of 90 samples were prepared to cover this study. Figure $5 \mathrm{~b}$ shows the sample location at each layer depth labeled C-Center, R-Right, L-Left, U-Up, and D-Down. Moreover, the water content and diameter at each layer were measured after excavating the area around the grout column. For dry and saturated conditions, a total of 6 periods were extracted in one depth from a random location of full dimensions of the JGC, which was grouped from S1 to S6.

\subsection{Test Methods}

\subsubsection{Compressive Strength Index (Is)}

The point load strength index test can be used for a preliminary level evaluation of spatial variability in sample compressive strength. Irregular lump samples can be tested by application of concentrated load through a pair of truncated, conical platens that is the biggest advantages of this testing method. Because of this reason, little or no specimen preparation is needed before testing. Figure 6a shows point load testing apparatus. It consists of a loading system typically comprised of a loading frame, platens, a measuring system for indicating load to measure the compressive strength index $\left(\mathrm{I}_{\mathrm{s}}\right)$ which is available in the geotechnical laboratory of Gaziantep University. The details of testing pro- 


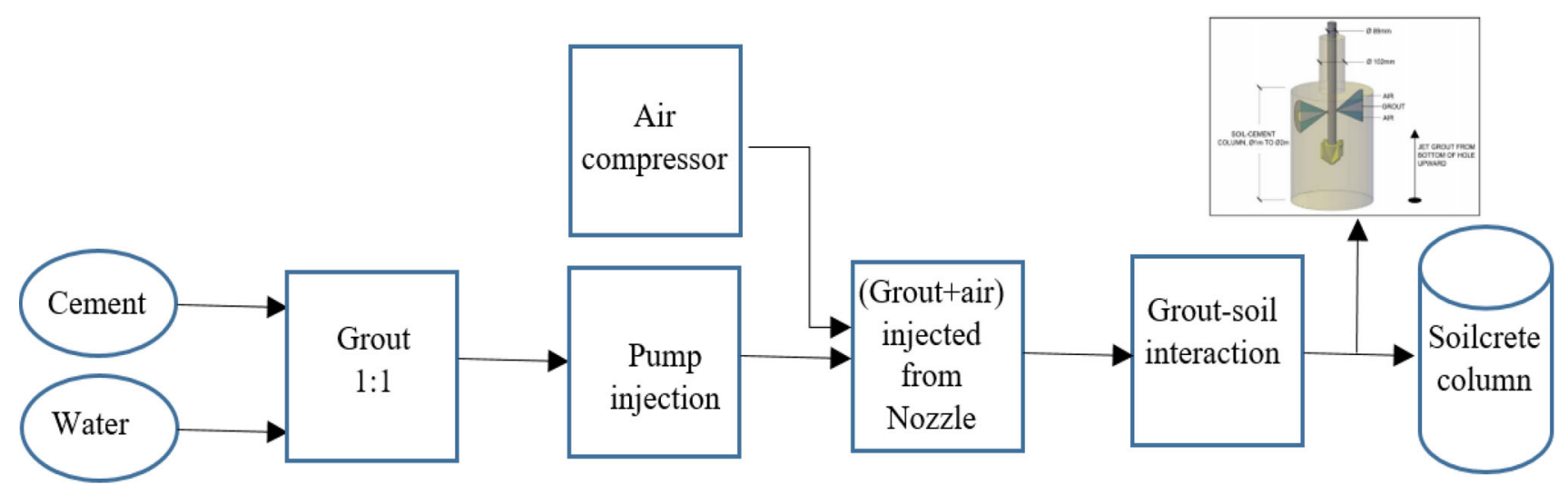

Fig. 4 Schedule diagram of jet grout column process

Fig. 5 JGC details: a full-scale dimension; b spacemen location; $\mathbf{c}$ test's samples

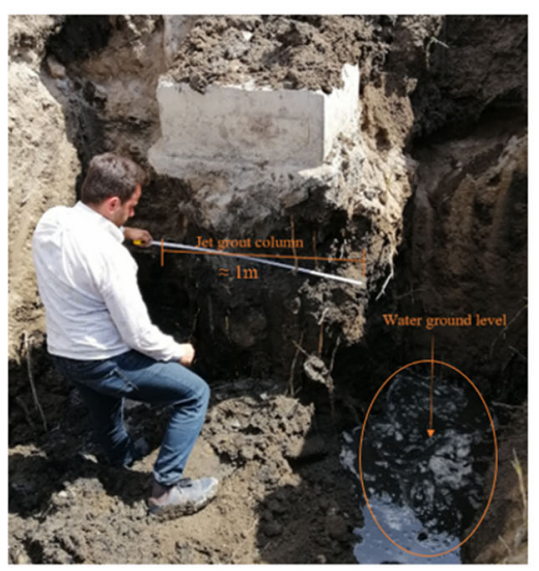

(a)

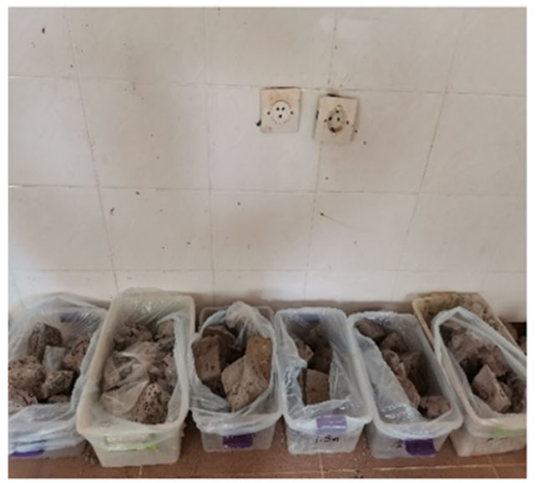

(c)

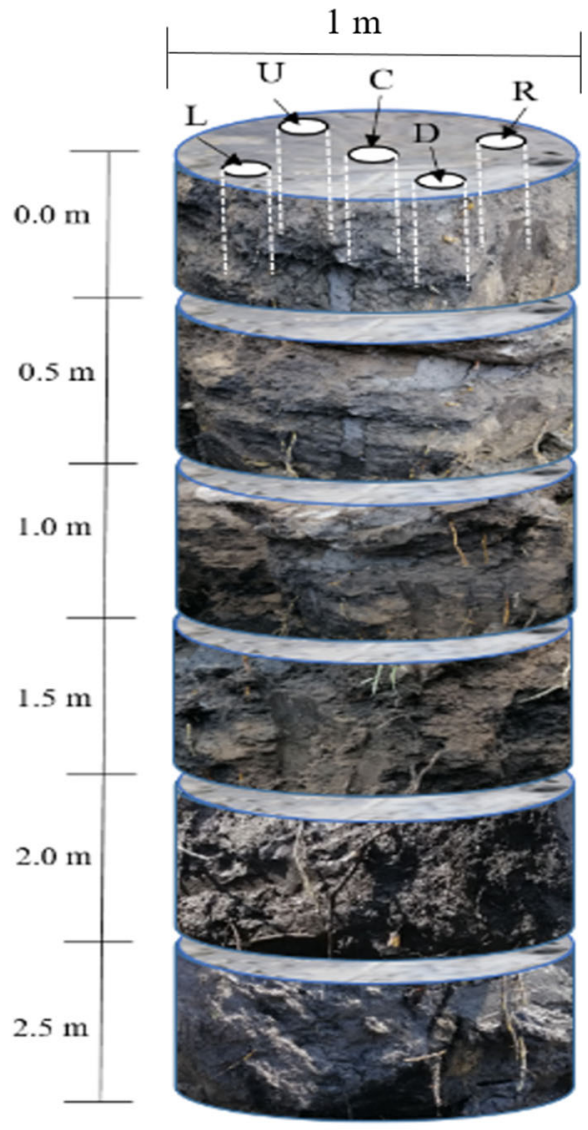

(b) cedures and calculations methods are given in ASTM D5731 [34]. The specimens used in this study are shown in Fig. 6b.

\subsubsection{Physical Properties (Water Absorption, Density, Porosity)}

Generally, water content, absorption, density, and porosity have important effect on compressive strength of soilcrete. The water content is the ratio, expressed as a percentage of the mass of pore water in a given mass of soil in its natural state to the mass of the dry soil solids. For the water absorption, the specimens are first dried in an oven for a 24 hours and then placed in a desiccator to cool. After cooling the specimens, they are weighed. The samples are then immersed in water at room temperature for 24 hours for saturation. Specimens are removed from water and dried with a damp cloth, and weighed. Using mass of absorb water and dry weight of the sample, water absorption is determined 
Table 5 Locations of the specimen test

\begin{tabular}{|c|c|c|c|c|}
\hline Labelle & Location & Depth (m) & Pressure (bar) & Rotation (rpm) \\
\hline S0.0-C & Center & 0 & 400 & 18 \\
\hline S0.0-R & Right & & & \\
\hline S0.0-L & Left & & & \\
\hline S0.0-U & $\mathrm{Up}$ & & & \\
\hline S0.0-D & Down & & & \\
\hline S0.5-C & Center & 0.5 & 400 & 18 \\
\hline S0.5-R & Right & & & \\
\hline S0.5-L & Left & & & \\
\hline S0.5-U & Up & & & \\
\hline S0.5-D & Down & & & \\
\hline S1.0-C & Center & 1 & 400 & 18 \\
\hline S1.0-R & Right & & & \\
\hline S1.0-L & Left & & & \\
\hline S1.0-U & Up & & & \\
\hline S1.0-D & Down & & & \\
\hline S1.5-C & Center & 1.5 & 400 & 18 \\
\hline S1.5-R & Right & & & \\
\hline S1.5-L & Left & & & \\
\hline $\mathrm{S} 1.5-\mathrm{U}$ & $\mathrm{Up}$ & & & \\
\hline S1.5-D & Down & & & \\
\hline S2.0-C & Center & 2 & 400 & 18 \\
\hline S2.0-R & Right & & & \\
\hline S2.0-L & Left & & & \\
\hline S2.0-U & Up & & & \\
\hline S2.0-D & Down & & & \\
\hline S2.5-C & Center & 2.5 & 400 & 18 \\
\hline S2.5-R & Right & & & \\
\hline S2.5-L & Left & & & \\
\hline $\mathrm{S} 2.5-\mathrm{U}$ & Up & & & \\
\hline S2.5-D & Down & & & \\
\hline
\end{tabular}

(ASTM D6473-15 [35]). In order to investigate the effect of water on compression index, three different series of test were carried out. These are dry, natural, and saturated conditions. In addition, the porosity of the samples was calculated according to ASTM C20-00 [36].

\subsubsection{Direct Shear Test}

A direct shear test was performed utilizing a conventional direct shear apparatus, as shown in Fig. 7. Single-stage direct shear tests were conducted under consolidated drained conditions to detect the interface shear properties under different normal stresses according to the ASTM D3080 [37] requirement. In this study, a shear test was conducted for soil-soil samples and soil-grout columns for comparison. Accordingly, the lower shear box was filled with grout sample for the first case and filled with soil for the second case with dimensions of $60 * 60 * 15 \mathrm{~mm}$; however, the upper shear box for all cases was filled with organic soil to measure the interface shear behavior of the soil-soil and soil-grout column. During the test, three different normal loads $(0.05,0.1$, and $0.2 \mathrm{kN})$ were used, and $1.0 \mathrm{~mm} / \mathrm{min}$ was considered the rate of shear box displacement for all tests.

\subsubsection{SEM Analysis}

The jet grout column was analyzed by scanning electron microscopy (SEM) in detail regarding the depth and direction parameters to propose the grout column sample transition zone variation between the present fibers and grout. The surface deformation of fibers after drying was also studied during the SEM test. To prepare the SEM samples, a sample was prepared for each parameter, and $2.0 \mathrm{~cm}$ was removed from both top and bottom sections of the specimens and existed from the middle region of the specimens where a $1 \mathrm{~cm}$ thickness was used for SEM analysis. 
Fig. 6 a Point load test, $\mathbf{b}$ Test samples

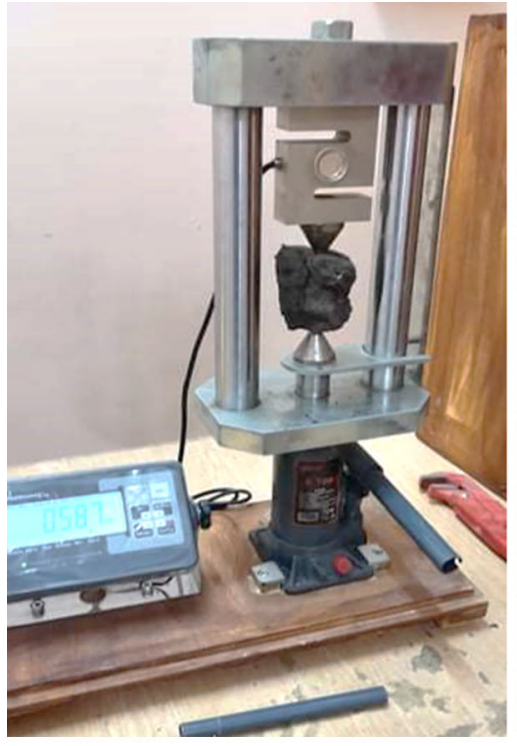

(a)

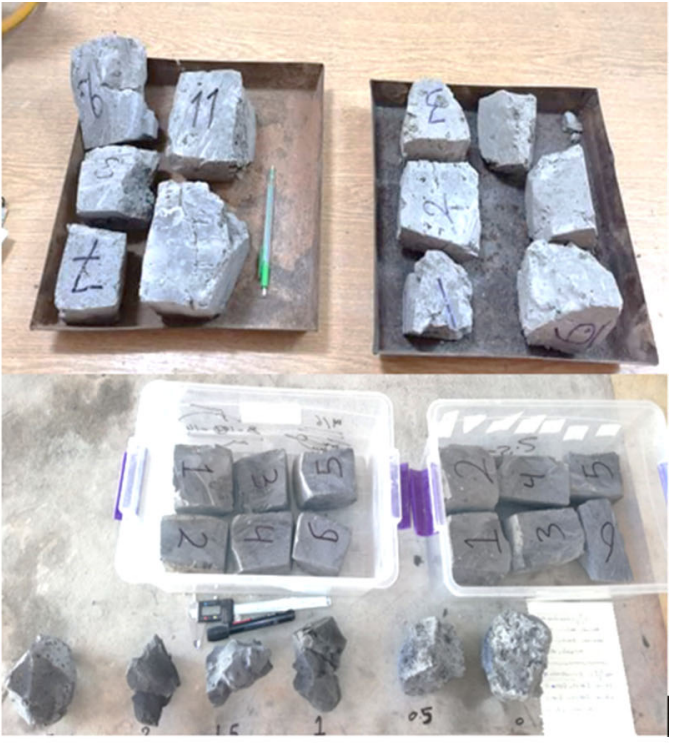

(b)

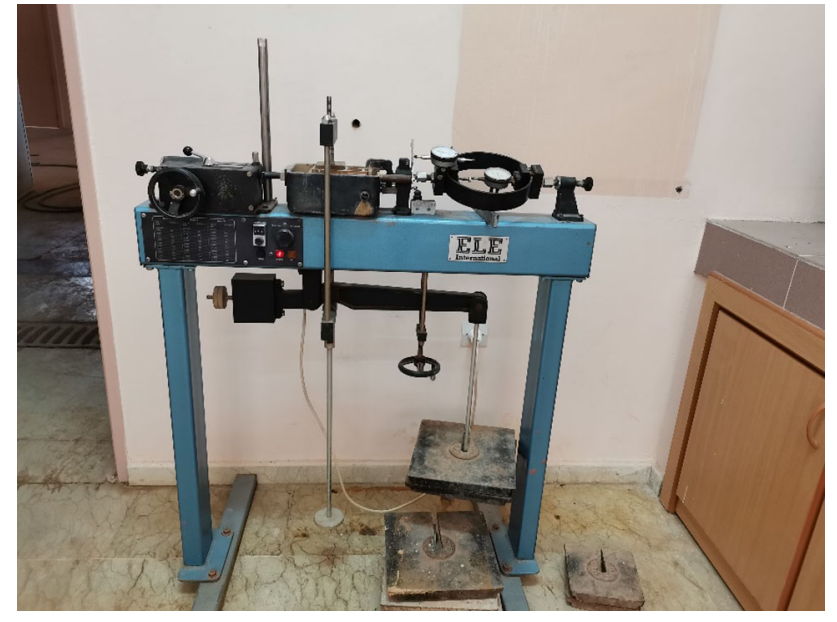

Fig. 7 Direct shear test

\section{Results and Discussion}

\subsection{Geomechanical Properties of Jet Grout Column}

\subsubsection{Compressive Strength Index in Natural Conditions}

According to ASTM D5731 requirements, the point load test is an index test by which the materials are classified as per the strength. This study presented the random variation of $\mathrm{I}_{\mathrm{S}}$ from the center to all directions, which is from the center to rightleft and up-down because of the indiscriminate distribution of soil. Therefore, the results showed that the $I_{S}$ at the center of the grouting column for all depths achieved maximum values compared with all other directions $(\mathrm{R}, \mathrm{L}, \mathrm{U}, \mathrm{D})$, as detailed in Fig. 8.
The strength indices of samples S0.0-C, S0.5-C, S1.0-C, S1.5-C, S2.0-C, and S2.5-C were measured as the highest values, which were $687,469,440,446,535$, and 479 $\mathrm{kPa}$, respectively. This can be attributed to the percentage of cement content covering the center of the grout column, which leads to an improved strength [38]. In addition, the $I_{S}$ decreased from the center to the edges at the same surface layer; thus, $687 \mathrm{kPa}$ of sample $\mathrm{S} 0-\mathrm{C}$ was considered to have the highest vole strength compared with S0-R, S0-L, S0-U, and S0-D, which were 491, 596, 507, and $648 \mathrm{kPa}$, respectively. The same approach of variation was recognized for all other depths. In addition, the compressive strength index $\left(I_{\mathrm{S}}\right)$ according to depth parameters has also been documented. $586 \mathrm{kPa}$ is the average $\mathrm{I}_{\mathrm{S}}$ of sample S0.0 and detected as the highest value compared with samples S0.5, S1.0, S1.5, S2.0, and S2.5, which had 419, 347, 317, 350, and $361 \mathrm{kPa}$, respectively, as shown in Fig. 8. The values randomly varied with increasing depth because of the increasing confining pressure of the soil, which affects the soilcrete compressive strength [39]. Previous studies documented that the technical specifications of jet grouting had a significant influence on the features of the JGC. The time interval per step, lifting step, and injection pressure were considered to be independent variables. The dependent variables were the strength and diameter of the column. The grout input rate increased with increasing the time interval per step. This increase in the mixing time of the cement and soil constructs a more homogenous specimen with fewer clayey clods at the core. In the case of unavailability of a weak failure path during unconfined compression testing, the strength of the soilcement increased as the lifting step of the drill stem decreased and the time interval per step increased [40]. Tadio (2016) [41] reported that the compressive strength increased with 
Fig. 8 Strength index of JGC in normal condition

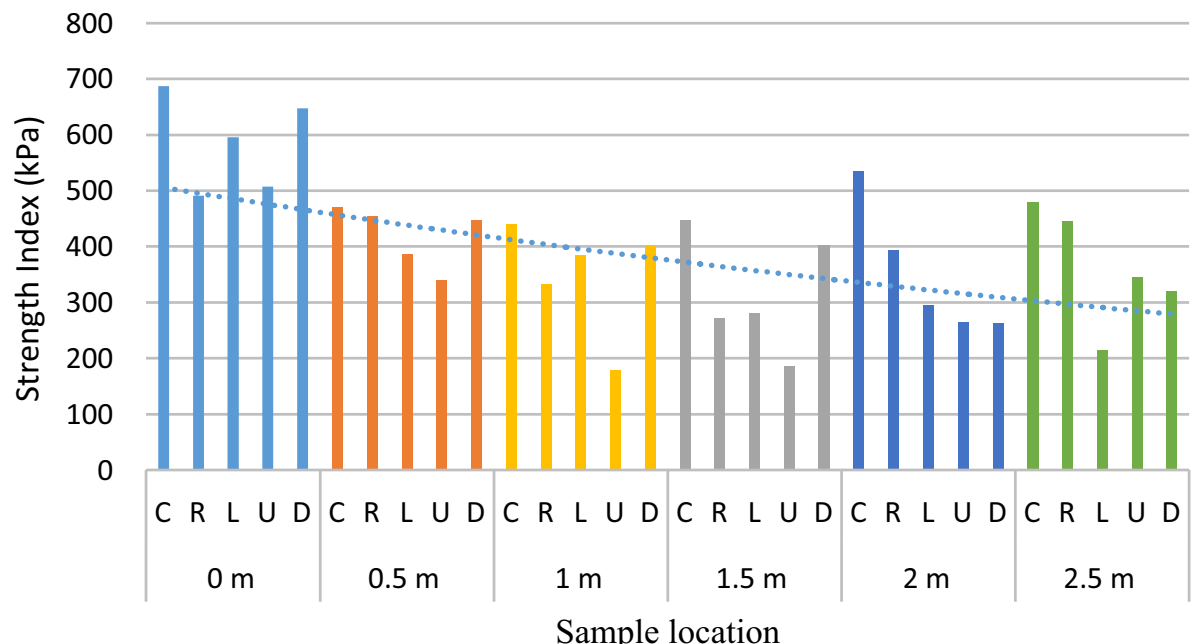

Fig. 9 Water content variation at center of JGC

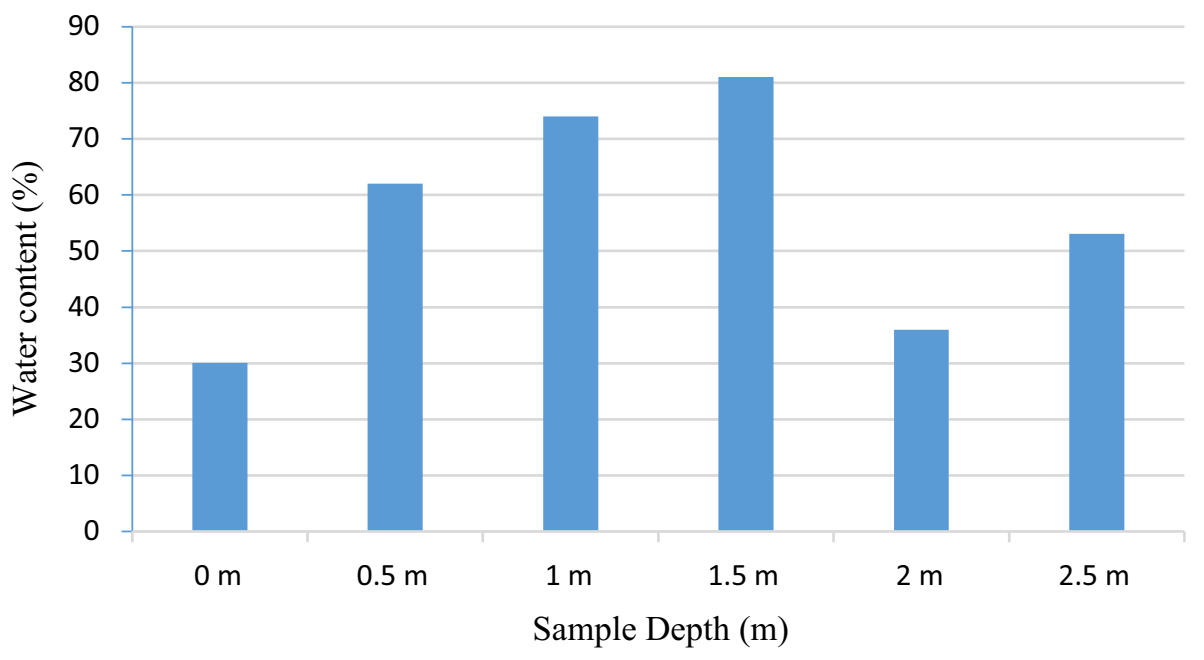

increasing cement percentage, and it was faster for formulations with $10 \%$ kaolinite. In addition, the water content at the center of the grouting column according to different depth layers can also be observed in Fig. 9. Organic soil distributions were not uninformed, which caused indiscriminate variations in water content. The minimum water content was measured at sample S0.0-C, which was $30 \%$, and the maximum value was achieved at sample S1.5-C (1.5 m depth), which was $81 \%$. Moreover, the percentages of the water content of specimens S0.5-C, S1.0-C, S2.0-C, and S2.5-Cm were $62,74,36$, and $53 \%$, respectively, and the non-uniform variation in water content and other properties of JGC were related to the non-homogeneity of soil distributions [42].

\subsubsection{Compressive Strength Index $\left(I_{s}\right)$ Under Saturated and Dry Conditions}

This study aims to determine the $\mathrm{I}_{\mathrm{S}}$ under saturated and dry conditions because the ground water level in this region varies significantly, reaching the ground surface, as presented in
Fig. 5a. Figure 10 presents the variation in the soilcrete $I_{s}$ values in dry and saturated conditions. The results indicated that the $\mathrm{I}_{\mathrm{S}}$ generally non-uniformly changed according to the locations; however, the $\mathrm{I}_{\mathrm{S}}$ values of all saturated samples was higher than that of the dry samples due to the presence of organic fibers, and the tensile strength of organic fibers generally increased with the increasing water content of samples, and led to decreasing shrinkage [43]. Thus, the minimum result of the $I_{S}$ dry saturated conditions was observed for samples $\mathrm{S} 1$ and $\mathrm{S} 3$ under both conditions (saturated and dry). The maximum value of the $I_{S}$ was measured at sample $S 3$ under saturated conditions, which was $424 \mathrm{kPa}$, and the $\mathrm{I}_{\mathrm{s}}$ values of test samples S1, S2, S4, S5, and S6 were 100, 225, 193, 226, and $239 \mathrm{kPa}$, respectively. Under dry conditions, $\mathrm{I}_{\mathrm{S}}$ value of sample $\mathrm{S} 6(119 \mathrm{kPa})$ is considered a maximum compared with samples S1, S2, S3, S4, and S5, which are 75, 99, 33, 83, and $115 \mathrm{kPa}$, respectively. From Fig. 10, it can be understood that the compressive strength of JGC under saturated conditions was higher than that of under dry conditions 
Fig. 10 Strength index of JGC in saturated and dry conditions

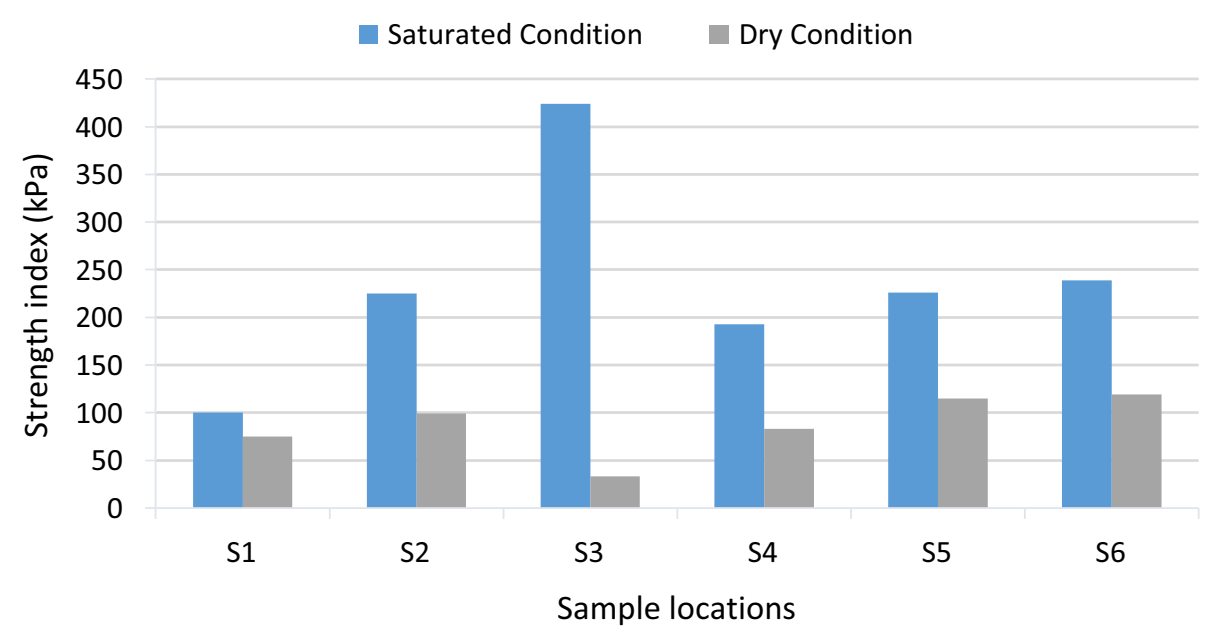

because of the presence of organic fibers, which improved the compressive strength [43]

\subsubsection{Water Absorption Test}

Generally, high water absorption capacity plays an important role in geomechanical and physical properties of grout column. In the present study, it can be seen that the results of water absorption for all test specimens roughly change from the center to right-left and up-down at different depths. Variations in water absorption with regard to the locations of the sample and depth parameters are presented in Fig. 11. Consequently, the results indicated that the water absorption at the center of the JGC achieved the minimum result compared with the edges, which means that the percentage of porosity gained the minimum level at the center of the grout column because the general relationship between water absorption and porosity is linear [44]. Therefore, 29, 33, 51, 53, 42, and $45 \%$ have been documented as a minimum percentage of water absorption at the center of the grout column for specimens S0.0-C, S0.5-C, S1.0-C, S1.5-C, S2.0-C, and S2.5-C that compared with directions $(\mathrm{R}, \mathrm{L}, \mathrm{U}, \mathrm{D})$ at each layer, which is $53,55,58$, and $47 \%$, respectively. In this study, the depth parameters were also studied, and the results predicted that the water absorption increase generally changed with increasing depth. Therefore, the minimum average percentage of water absorption was obtained at sample S0.0, which was $33 \%$, and compared with S0.5, S1.0, S1.5, S2.0, and $\mathrm{S} 2.5$, the percentages were $41,62,70,49$, and $54 \%$, respectively. No uniform variation was observed due to the depth, which means that the organic soils are not homogenously distributed with respect to the depth parameter [42].

\subsubsection{Density of Jet Grout Column}

Figure 12 presents the variation in the JGC density versus different directions and depths. As a result, a significant variation in density was presented according to locations, which is from the center to all other directions $(\mathrm{R}, \mathrm{L}, \mathrm{U}$, $\mathrm{D})$, and the same approach has been detected in the depth parameter; therefore, the density at the center of grouting column has achieved the highest result compared with all other directions, which are 1.24, 1.25, 0.95, 0.89, 1.05, and 1.03 $\mathrm{gm} / \mathrm{cm}^{3}$ at samples S0.0-C, S0.5-C, S1.0-C, S1.5-C, S2.0-C, and $\mathrm{S} 2.5-\mathrm{C}$, respectively, which means that cement dosage covered the majority of grout column's center that leads to increase the density [45]. In addition, water absorption reached the minimum level at the center of the grout column because the relationship between water absorption and porosity was inversely related. Statistical analysis showed significant correlations at the $95 \%$ confidence level between density and water absorption [46]. The present study reported that the density randomly increased and decreased from the center to the edges at the same layer; hence, sample S0.0-R $\left(1.25 \mathrm{gm} / \mathrm{cm}^{3}\right)$ was detected as the highest value compared with samples S0.0-C, S0.0-L, S0.0-U, and S0.0-D, such as $1.24,1.14,1.24$, and $1.21 \mathrm{gm} / \mathrm{cm}^{3}$, respectively, and the same approach of variation was recognized for all other depths. A reduction in density means increasing the amount of organic soil clods. In total, the density in all states decreases when increasing the soil quantity [47]. Variation in density of soilcrete with depth were also analyzed. For this purpose, six different depths were chosen for sampling starting from ground surface to a depth of -2.50 . $\mathrm{m}$. Average density for each depth $(0.0 \mathrm{~m}, 0.5 \mathrm{~m}, 1.0 \mathrm{~m}, 1.5 \mathrm{~m}, 2.0 \mathrm{~m}$, and $2.5 \mathrm{~m})$ was calculated. Average densities for samples S0.0, S0.5, S1.0, S1.5, S2.0, and S2.5 were 1.216, 1.158, 0.875, 0.821, 0.995, and $0.973 \mathrm{gm} / \mathrm{cm}^{3}$, respectively, which indicates that the density has been non-uniformly changed because of the nonhomogeneous distribution of soil and confining pressure of soil [39, 42]. In addition, the average value of the density achieved the highest results at specimen S0.0 m compared with specimens S0.5, S1.0, S1.5, S2.0, and S2.5 m. Thus, 1.216 and $0.821 \mathrm{gm} / \mathrm{cm}^{3}$ were noted as the maximum and 
Fig. 11 Water absorption variation of JGC

Fig. 12 Density variation of JGC

Fig. 13 Porosity variation of JGC
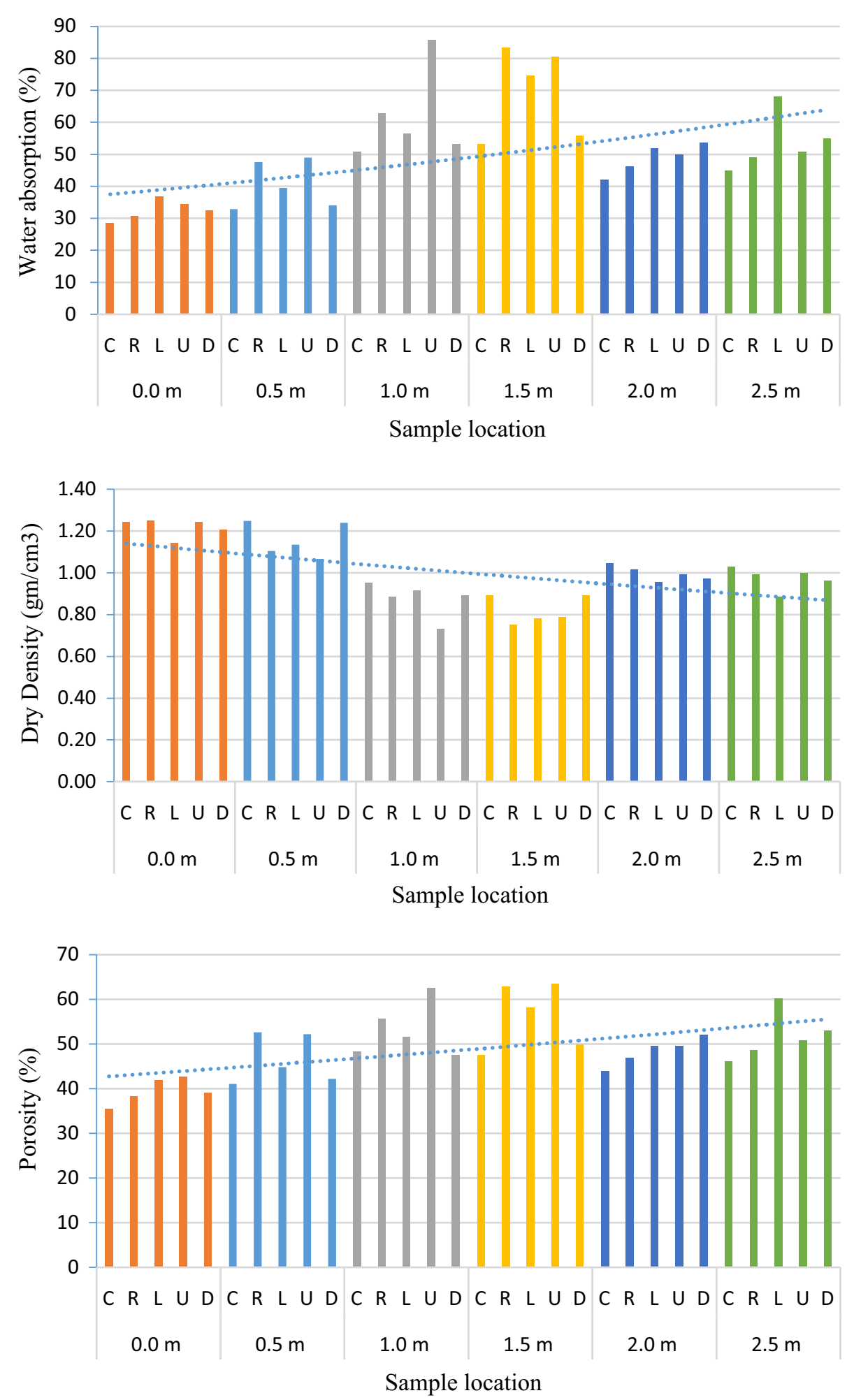

minimum average densities of sample S0.0. and S1.5. Furthermore, the average densities of specimens S0.5, S1.0, S2.0, and S2.5 m depth were not uniformly changed and were $1.158,0.875,0.995$, and $0.97 \mathrm{~s} \mathrm{gm} / \mathrm{cm}^{3}$, respectively.

\subsubsection{Porosity}

Figure 13 shows the variation in the jet grout porosity versus different parameters, such as directions and depths. The porosity test calculated the volume of the void fraction in the 
specimens according to slandered requirements. This case study reported an obvious change in the percentage of porosity from the center of the JGC to the top-down and right-left and at different depths $(0.0,0.5,1.0,1.5,2.0$, and $2.5 \mathrm{~m}$ depth). Therefore, $35,41,48,48,44$, and $46 \%$ were measured for specimens S0.0-C, S0.5-C, S1.0-C, S1.5-C, S2.0-C, and $\mathrm{S} 2.5-\mathrm{C}$, respectively, that were recognized as minimum values compared with other trends ( $\mathrm{R}, \mathrm{L}, \mathrm{U}$, and $\mathrm{D})$.

It can be understood that the pure cement paste covers the center of the grout column, and the dry density gains the maximum value because the porosity-density relationship is inversely related [47]. The percentage of porosity nongradually varied from the center to right-left and up — down at the same depth; consequently, the porosities of specimens S0.0-C, S0.0-R, S0.0-L, S0.0-U, and S0.0-D were 35, 38, 42, 43 , and $39 \%$, respectively. The same approach has been proposed for other depths, which means that the distribution of organic soil is not homogenous and has high compressibility [48]. On the other hand, the porosity variation according to the depth parameters was also measured, and the results indicated that the porosity normally changed with increasing depth. Thus, the average porosity gained the highest results at sample S1.5 (56\%) compared with samples S0.0, S0.5, S1.0, S2.0, and S2.5 at 39, 47, 53, 48, and 52\%, respectively. It can be understood that the maximum percentage of porosity caused a decrease in the strength properties of JGC because of the linear reversing relationship of strength and porosity $[49,50]$.

\subsubsection{Organic Soil: Jet Grout Column Interface Friction}

This paper reported the variation in shear-normal stress to predict the interface friction of organic soil-grout columns with horizontal surface planes at $\Phi=0^{\circ}$ according to ASTM D3080-04, as detailed in Fig. 14. According to MohrCoulomb failure theories, the shear stress gradually increased with increasing normal stress. This approach was reported by utilizing three normal stresses versus shear stresses for the test. During the normal stress-shear stress curve, the linear retraction line is drawn through the set of interfaces [51]. In addition, cohesion (c) of $10 \mathrm{kPa}$ shear deformation was used to measure the shear strength value of the grout column and organic soil, which provides a fit linear line with $\mathrm{R}^{2}$ equal to 0.95 . The friction angle $(\varphi)$ was measured from the curve shown in Fig. 14.

The shear stress increased with increasing normal stress, and there was a significant shear interface between the JGC and organic soil; the friction angle $(\varphi)$ exceeded $42^{\circ}$, and the cohesion factor (c) was $10 \mathrm{kPa}$, which is less than the soil-soil results $\left(\varphi=45^{\circ}, c=27.78 \mathrm{kPa}\right)$. Moreover, it is higher than concrete because the roughness surface directly relates to a variation in shear [18]. The comparison of interface shear results showed that the sand and water contents of organic soil have a clear influence on the mechanical properties at the organic soil-sand mixture interface and other construction materials, such as wood, rough steel, and smooth steel. Moreover, concrete and wood interface friction decreased with increasing water content compared with the friction angle in rough and smooth steel [18].

Figure 15 presents the interface shear test of the organic soil-jet grout column for the horizontal plane at $\varphi=0^{\circ}$ with respect to the normal stress under normal conditions. The interface shear of soil-soil was also presented in this study for comparison. In the shear stress-horizontal displacement curve, the variation of shear stress for soil-grout column and soil-soil specimens have been the same approach for increasing. Thus, the interface shear stress dramatically increased with increasing horizontal displacement until reaching the highest range of shear strength, after which it remained constant or decreased slightly. As a result, the shear strength and displacements gradually increase with the application of normal stress, which means that the increase in normal stress leads to an increase in the frictional resistance between the JGC and organic soil. The results of the study are acceptable compared with those of a previous study [51]. In addition, the results indicated that the maximum shear stress was observed at the interface stress of the soil-jet grout column and soilsoil, which were 62 and $55 \mathrm{kPa}$ at $56 \mathrm{kPa}$ normal stress, respectively. This can be attributed to the fact that the surface of the grout column plays the main role and is acceptable compared with the case study of Canakci et al. (2016) [18]. The highest values of shear stress were achieved at the interface between organic soil and concrete compared with steel and wood; however, the lowest values were obtained at the interface between the organic soil and smooth steel.

\subsection{SEM Studies}

SEM micrographs of JGC were studied in this paper. Three different specimen locations were taken at the same layer, from the center to the edges on the same line, such as C, R1, and R2. Two different depths were also measured as parameters, such as 0.5 and $2.5 \mathrm{~m}$ depth, which were utilized to analyze the cement-past injection during the grouting process in the organic soil, as shown in Fig. 16a-g, respectively. In addition, the samples labeled C- 0.5 and C-2.5 indicate sampling from the center at depths of 0.5 and $2.5 \mathrm{~m}$, and R1-0.5, R2-0.5, R1-2.5, and R2-2.5 indicate that two samples are taken from the center of the grout column to the right. Generally, the microstructures of C- 0.5 and C- 2.5 predicted that the percentage of cement-past covered a large area of grout column (Fig. 16a and b) with a few saturated organic fibers; therefore, these fibers at saturated conditions lead to an increase in the compressive strength index with general properties of the grouting column, such as ductility [47]. Additionally, Kriker et al. (2005) [43] concluded 
Fig. 14 Shear envelops of organic soil-jet grout column interface
Fig. 15 Shear stress vs horizontal displacement curves of organic soil-jet grout column
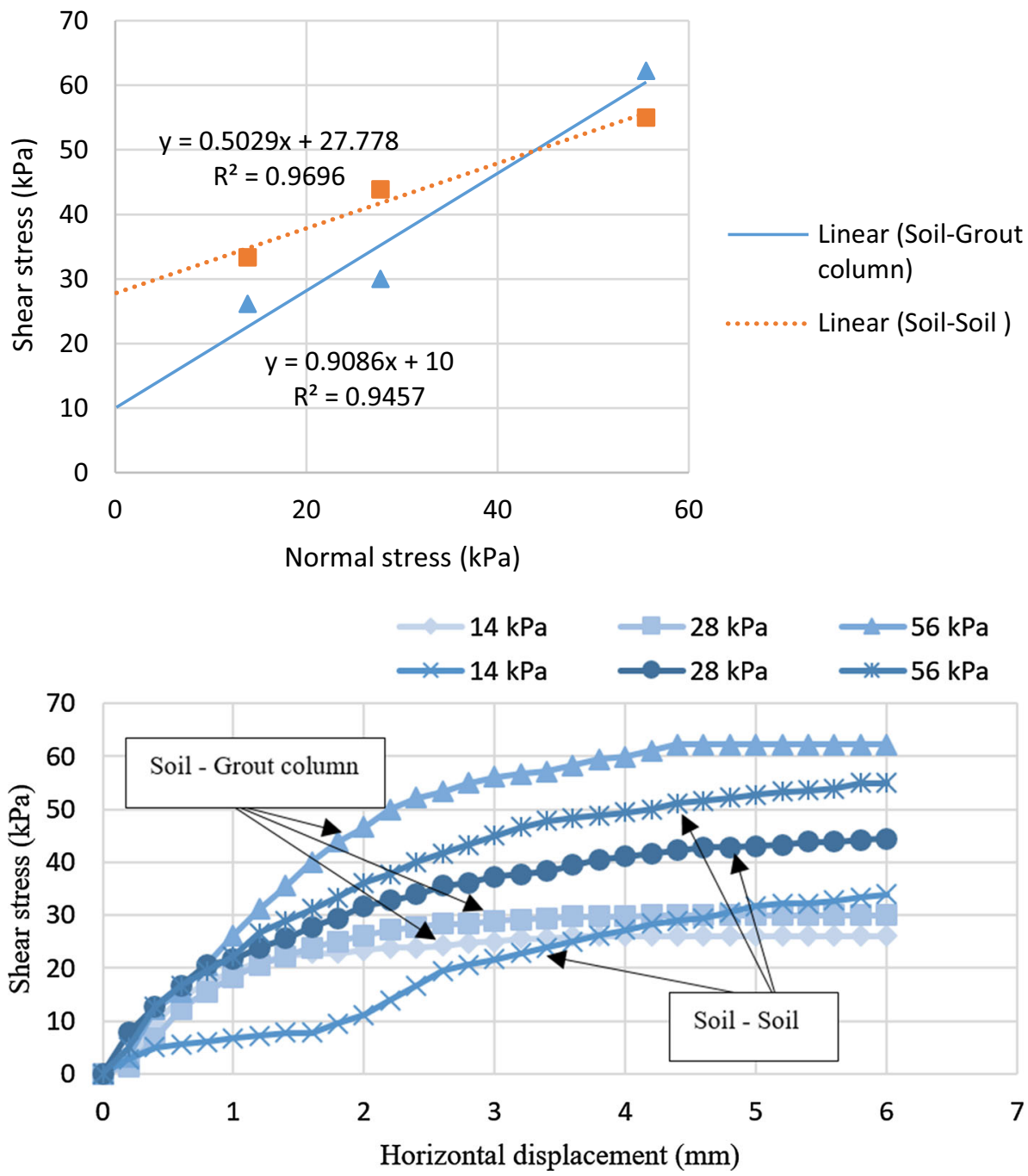

that organic vegetable fiber had a beneficial influence on the ductility properties after water curing. Organic fibers and pores were also visible in the specimens after drying conditions, as displayed in Fig. 16c and d, respectively, and it was reported that the organic fibers squeezed after drying the sample caused voids. However, the concentration of soil increased with shifting to the edges, which caused a decrease in the compressive strength index of the grouting column, as shown in Fig. 16b-e. Figure 16g presents the pure organic soil before injecting cement-past into the soil. According to the SEM approach of grouting columns, microstructural studies have been improved by adding MK to the mix, which leads to a decrease in microcracking, porosity, and structure of dense cement past. However, a different consideration can be recognized with increasing soil concentration, which leads to an increase in the percentage of porosity and voids that influence compressive strength development [52].

\subsection{Theoretical Approach of Diameter Prediction}

Many researchers have participated to enhance the theoretical approach to predict column diameter according to grouting specifications [11, 22]-[25]. In addition, the full-scale grouting column results were confirmed to compare the measured diameter with the calculated diameter utilizing the existing relation. Flora et al. (2013) [25] concluded that the most overall relation, which indicates the parameters of energy exerted during injection, soil type, and injection specifications, was presented as the following equation:

$D m=D_{\text {ref }} \cdot\left(\frac{\alpha_{E} \cdot A^{*} \cdot E^{\prime}{ }_{n}}{7.5 * 10}\right)^{\beta} \cdot\left(\frac{N_{\mathrm{SPT}}}{10}\right)^{\delta}$

where $N_{\text {SPT }}$ is the standard penetration number of the soil before improvement, $E_{n}$ is the injection energy at the nozzle per unit length of grouting column $(\mathrm{MJ} / \mathrm{m})$, and $\alpha_{E}$ is a dimensionless parameter regarding the grout method, which is for double-fluid jet grouting equal to 6 . Moreover, $D_{\text {ref }}$ is 
Fig. 16 SEM photographs of grout column: a C- 0.5 , b C-2.5, c R1-0.5, d R2-0.5, e R1-2.5, f R2-2.5, $\mathrm{g}$ organic soil

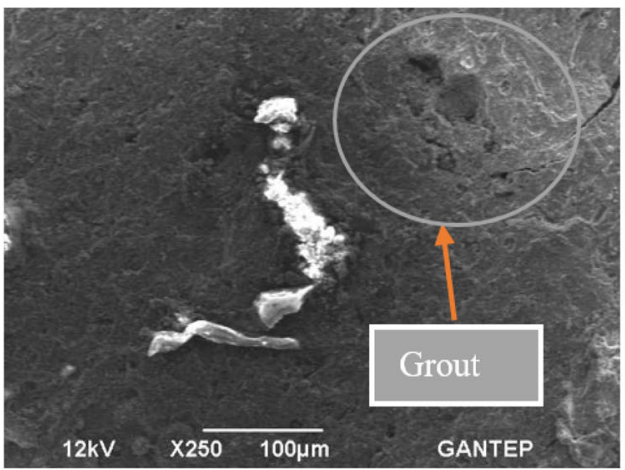

(a) C-0.5

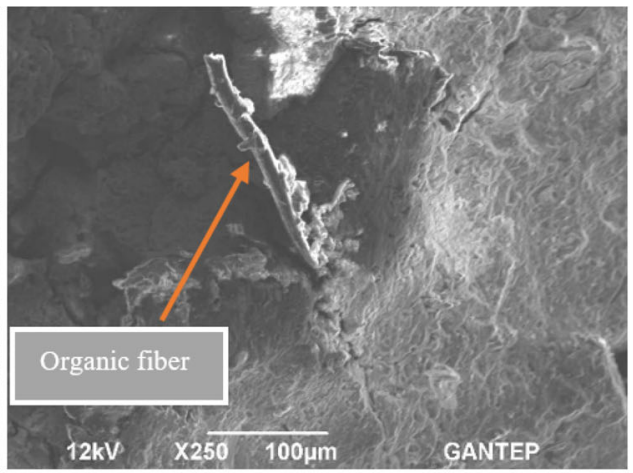

(b) C-2.5

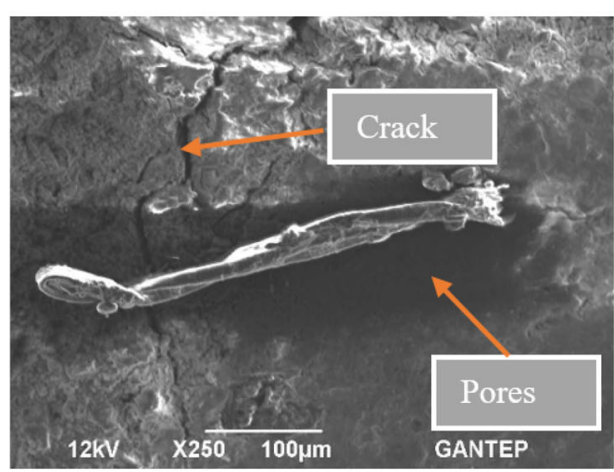

(c) R1-0.5

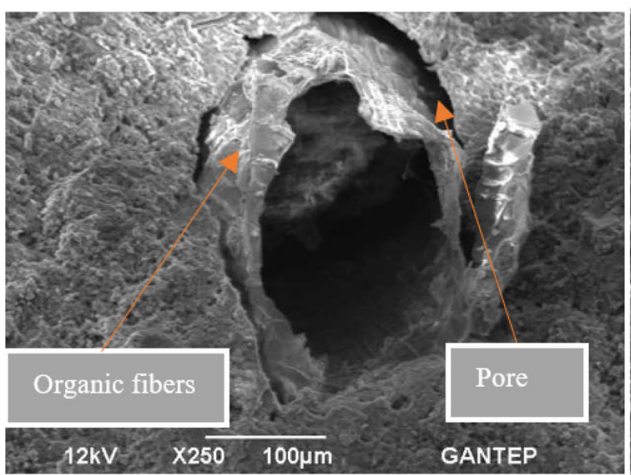

(e) R1-2.5

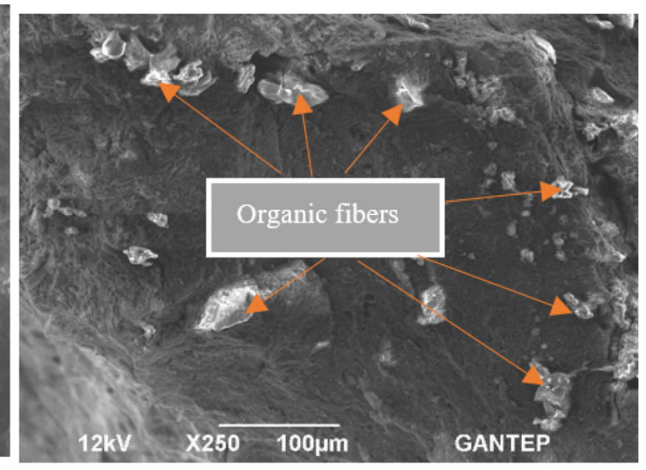

(d) R2-0.5

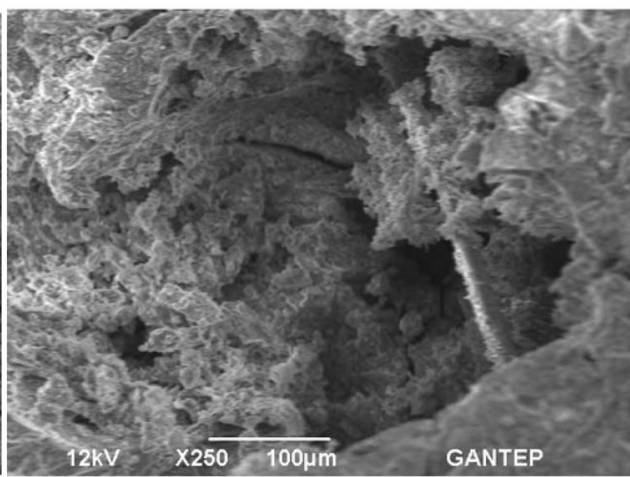

(f) $\mathrm{R} 2-2.5$

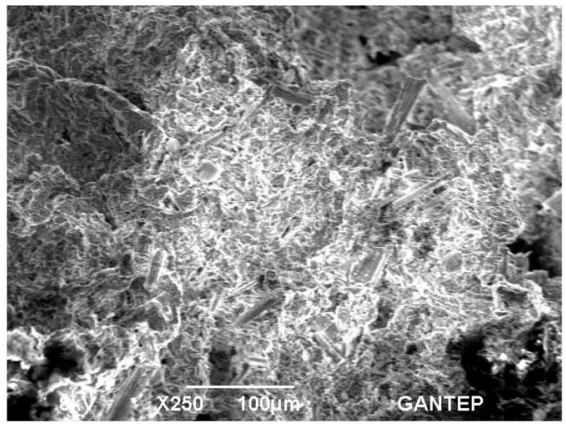

(g) Organic soil

the reference diameter that is considered according to soil type, which is $D_{\text {ref }}$ equal to 0.5 for organic soil. The dimen- sionless parameter is denoted as $A^{*}$ and utilized according to the $\mathrm{W} / \mathrm{C}$ ratio, which is $A^{*}$ equal to 7.5 at $\mathrm{W} / \mathrm{C}$ equal to 
one. Model parameters ( $\beta$ and $\delta$ ) for organic soil are equal to 0.2 and -0.25 , respectively [26]. In addition, the factors influencing the diameter of the JGC require careful consideration for a better prediction of column diameters [53]. Thus, this equation includes all requirement factors to predict the diameter. In this study, the average $N_{S P T}$ of the present soil is equal to 10. As a confirmation of this equation during the present study, the measurement diameter was $0.83 \mathrm{~m}$, and the possibility of using this equation in organic soil was proven to be $0.75 \mathrm{~m}$ compared with the full-scale diameter of JGC.

\section{Conclusion}

Founded on this investigational study, jet grouting techniques were used in organic soil to study the property variation of jet grout (soilcrete) columns in the field. A full-scale JGC constructed and measured the diameter to compare with values estimated using existing relations. The organic jet grouting interaction was assessed through a microstructural approach. All previous studies took the sample from the center to show the properties of the grouting column, but in fact, the column properties (mechanical, physical, and microstructure properties) from the center did not represent all other locations according to the direction and depth parameters, as follows:

- This study presented the indiscriminate variation in the $\mathrm{I}_{\mathrm{S}}$ from the center to other directions because of the nonuniformity of the soil distribution. The test results showed that the $\mathrm{I}_{\mathrm{S}}$ of samples S0.0-C, S0.5-C, S1.0-C, S1.5-C, S2.0-C, and S2.5-C had the highest measured values, which were $687,469,440,446,535$, and $479 \mathrm{kPa}$, respectively. This means that the pure cement paste covers the center of the grout column. The $\mathrm{I}_{\mathrm{s}}$ values are different at five locations within the same depth. Calculated maximum change is $28 \%$ at the ground surface. The average $\mathrm{I}_{\mathrm{S}}$ values of sample S0.0 was $586 \mathrm{kPa}$. It is the highest value compared with samples S0.5, S1.0, S1.5, S2.0, and S2.5, that were $419,347,317,350$, and $361 \mathrm{kPa}$, respectively. The maximum change in average $I_{S}$ value within depth is $46 \%$.

- During this case study, the $I_{\mathrm{S}}$ values in saturated and dry conditions were reported and investigated in a one-meter depth hardened JGC. In addition, the $\mathrm{I}_{\mathrm{s}}$ of the JGC in saturated conditions higher than in dry conditions, for example; the $\mathrm{I}_{\mathrm{S}}$ values of samples $\mathrm{S} 1, \mathrm{~S} 2, \mathrm{~S} 3, \mathrm{~S} 4, \mathrm{~S} 5$, and S6 were 100, 225, 424, 193, 226, and $239 \mathrm{kPa}$, while for dry condition, the $\mathrm{I}_{\mathrm{s}}$ are $75,99,33,83,115$, and $119 \mathrm{kPa}$, respectively, because of the presenting organic fiber in the column, which leads to increasing the bonding in the column. In addition, the $I_{S}$ values of the grouting column roughly increased with increasing density.
- The water absorption at the center of the JGC achieved the minimum result for all depths $(0.0,0.5,1.0,1.5,2.0$, and $2.5 \mathrm{~m}$ ). These are 29, 33, 51, 53, 42, and 45\%, respectively. These values are higher at outer side $(R, L, U, D)$ of the soilcrete compare to the center. The minimum average water absorption was obtained on sample S0.0, which was $29 \%$.

- The highest dry densities were obtained at the center of JGC compared with the edges for all depths. The dry densities of the soilcrete at center in different depths were $1.24,1.25,0.95,0.89,1.05$, and $1.03 \mathrm{~g} / \mathrm{cm}^{3}$ for samples S0.0-C, S0.5-C, S1.0-C, S1.5-C, S2.0-C, and S2.5-C, respectively. The maximum and minimum densities are 1.25 and $0.89 \mathrm{~g} / \mathrm{cm}^{3}$, respectively. The lowest average porosity was $39.4 \%$. It is also obtained at the center of soilcrete.

- The interface shear behavior of the soil-jet grouting column and soil-soil were evaluated using a direct shear test method, and there was a significant shear interface between the JGC and organic soil, which had $\varphi=42^{\circ}$ and $\mathrm{c}=$ $10 \mathrm{kPa}$, which was less than the soil-soil results $\left(\varphi=45^{\circ}\right.$, $\mathrm{c}=27.8 \mathrm{kPa}$ ). Compared with the previous study, the interface friction was higher than that of all other construction materials, such as concrete, wood, rough steel, and smooth steel, which is directly related to the rough surface of the materials.

- SEM showed that the availability of organic fiber in the grout column leads to an improvement in the $\mathrm{I}_{\mathrm{S}}$ and other general properties under saturated conditions since one of the organic fiber behaviors under wet conditions is improving the bond strength between the material particles and leads to an increase in shrinkage. On the other hand, organic fiber was squeezed after drying the specimen for a long time, which caused an increase in the porosity and a decrease in the density of the grouting column.

- The theoretical approach of diameter prediction in this study was also approved. The comparison of the experimental results and diameter calculations of this study reported that the possibility of using the diameter equation in organic soil has been proven compared with the full-scale diameter equation.

- Based on the results, it is showed that sample taken at the center of the JGC is not representing properties of whole soilcrete. It is better to take samples at different location on the JGC and use average geotechnical properties for design purpose.

Acknowledgements The experimental study of this present paper has been conducted at the Civil Engineering Laboratory of University of Gaziantep, through the Ph.D. thesis of First author. The authors would like to present their gratitude to the anonymous reviewers for carefully reviewing the manuscript and providing valuable comments. 


\section{References}

1. Tiwari, S.K.; Kumawat, N.K.: Recent development in ground improvement techniques - a review. Int. J. Recent Dev. Eng. Technol. 2(3), 67-77 (2014)

2. Croce, P.; Flora, A.; Modoni, G.: Jet Grouting: Technology, Design and Control. CRC Press, Boca Raton (2014)

3. Kirsch, K.; Bell, A.: Ground Improvement. CRC Press, Boca Raton (2012)

4. Han, J.: Principles and practice of ground improvement. John Wiley I\& Sons, Hoboken (2015)

5. Tiwari, S.K., et al.: Jet grouting: technology, design and control. Int. J. Recent Dev. Eng. Technol. 2(3), 67-77 (2014)

6. Tinoco, J.; Correia, A.G.; Cortez, P.: A novel approach to predicting Young's modulus of jet grouting laboratory formulations over time using data mining techniques. Eng. Geol. 169, 50-60 (2014)

7. Busato, L., et al.: Combined geophysical surveys for the characterization of a reconstructed river embankment. Eng. Geol. 211, 74-84 (2016)

8. Essler, R.: The design of jet grouting from concept to execution. Grout. Deep Mix. 2012, 2071-2081 (2012)

9. Wang, Z.-F.; Shen, S.-L.; Yang, J.: Estimation of the diameter of jetgrouted column based on turbulent kinematic flow theory. Grout. Deep Mix 2012, 2044-2051 (2012)

10. Erkan, I.H.; Tan, Ö.: The effect of pulling and rotation speed on the jet grout columns. Int. J. Civ. Environ. Eng. 10(12), 1690-1694 (2017)

11. Burke, G.K.: The state of the practice of jet grouting. Grout. Deep Mix 2012, 74-88 (2012)

12. Njock, P.G.A.; Chen, J.; Modoni, G.; Arulrajah, A.; Kim, Y.H.: A review of jet grouting practice and development. Arab. J. Geosci. 11(16) (2018). Doi: https://doi.org/10.1007/s12517-018-3809-7.

13. Jarret, R.L.: Effects of chemical growth retardants on growth and development of sweetpotato (Ipomoea batatas (L.) Lam.) in vitro. J. Plant Growth Regul. 16(4), 227-231 (1997)

14. Magnan, J.P.: Methods to reduce the settlement of embankments on soft clay: a review. Vert. Horiz. Deform. Found. Embank. pp. 77-91 (1994)

15. Huang, J.; Han, J.; Oztoprak, S.: Coupled mechanical and hydraulic modeling of geosynthetic-reinforced column-supported embankments. J. Geotech. Geoenvironmental Eng. 135(8), 1011-1021 (2009)

16. Güllü, H.; Canakci, H.; Al Zangana, I.F.: Use of cement based grout with glass powder for deep mixing. Constr. Build. Mater. 137, 12-20 (2017)

17. Ho, L.S.; Nakarai, K.; Ogawa, Y.; Sasaki, T.; Morioka, M.: Strength development of cement-treated soils: effects of water content, carbonation, and pozzolanic reaction under drying curing condition. Constr. Build. Mater. 134, 703-712 (2017). https://doi.org/10.101 6/j.conbuildmat.2016.12.065

18. Canakci, H.; Hamed, M.; Celik, F.; Sidik, W.; Eviz, F.: Friction characteristics of organic soil with construction materials. Soils Found. 56(6), 965-972 (2016)

19. Uesugi, M.; Kishida, H.: Influential factors of friction between steel and dry sands. Soils Found. 26(2), 33-46 (1986)

20. Lambe, T.V.: et Whitman R. V: Soil mechanics, SI version. J. Wiley Sons 1, 979 (1979)

21. Yoshimi, Y.; Kishida, T.: A ring torsion apparatus for evaluating friction between soil and metal surfaces. Geotech. Test. J. 4(4), $145-152$ (1981)

22. Carnevale, F.; Belloni, L.; Grassi, A.: Evaluation of diameter and characteristics of jet grouting columns-analytical approach. Grout. Deep Mix. 2012, 2061-2070 (2012)
23. Coelho, S.; da Fonseca, A.V.; Cebola, D.; Anta, N.: The use of drilling parameters recording as a tool for quality control in jet grouting treatments. Grout. Deep Mix. 2012, 1484-1493 (2012)

24. Thiyyakkandi, S.; McVay, M.; Bloomquist, D.; Lai, P.: Measured and predicted response of a new jetted and grouted precast pile with membranes in cohesionless soils. J. Geotech. Geoenviron. Eng. 139(8), 1334-1345 (2013)

25. Flora, A.; Modoni, G.; Lirer, S.; Croce, P.: The diameter of single, double and triple fluid jet grouting columns: prediction method and field trial results. Géotechnique 63(11), 934-945 (2013)

26. Croce, P.; Flora, A.: Analysis of single-fluid jet grouting. Geotechnique 50(6), 739-748 (2000)

27. Goh, A.T.C.: Deterministic and reliability assessment of basal heave stability for braced excavations with jet grout base slab. Eng. Geol. 218, 63-69 (2017)

28. Sujatha, A.; Govindaraju, L.; Shivakumar, N.; Devaraj, V.: Fuzzy knowledge based system for suitability of soils in airfield applications. Civ. Eng. J. 7(1), 140-152 (2021)

29. Fazelabdolabadi, B.; Golestan, M.H.: Towards Bayesian quantification of permeability in micro-scale porous structures. HighTech Innov. J. 1(4), 148-160 (2020). https://doi.org/10.28991/hij-202001-04-02

30. Kaur, A.; Singh, H.; Jha, J.N.: Numerical study of laterally loaded piles in soft clay overlying dense sand. Civ. Eng. J. 7(4), 730-746 (2021)

31. ASTM: ASTM D2974-14 Standard Test Methods for Moisture, Ash, and Organic Matter of Peat and Other. Am. Soc. Test. Methods C, 1-4 (2014). Doi: https://doi.org/10.1520/D2974-14.obtaining.

32. ASTM D4318, ASTM D 4318-10, and A. D4318-05: Standard test methods for liquid limit, plastic limit, and plasticity index of soils. Report 04, 1-14, (2005). March 2010. Doi: https://doi.org/1 $0.1520 / \mathrm{D} 4318-17 \mathrm{E} 01$

33. A. ASTM: C150/C150M-17, standard specification for Portland cement. Am. Soc. Test. Mater. West Conshohocken, PA, USA (2017)

34. ASTM: Standard test method for determination of the point load strength index of rock 1. Rock Mech. 22(2), 1-9 (1985). Doi: https://doi.org/10.1520/D5731-16.methods.

35. AASHTO T85: Standard test method for specific gravity and absorption of coarse aggregate. Am. Soc. Test. Mater., pp. 1-9 (2015). Doi: https://doi.org/10.1520/D6473-15.responsibility.

36. ASTM C20-00: Standard Test methods for apparent porosity, water absorption, apparent specific gravity, and bulk density of burned refractory brick and shapes by boiling water,

37. ASTM D3080: Standard test method for direct shear test of soils under consolidated drained conditions. ASTM Int., Conshohocken, PA, USA, pp. 343-351 (2011). Doi: https://doi.org/10.1520/D308 0 .

38. Uddin, K.; Balasubramaniam, A.S.; Bergado, D.T.: Engineering behavior of cement-treated Bangkok soft clay. Geotech. Eng. 28, 89-119 (1997)

39. Nikbakhtan, B.; Osanloo, M.: Effect of grout pressure and grout flow on soil physical and mechanical properties in jet grouting operations. Int. J. Rock Mech. Min. Sci. 46(3), 498-505 (2009)

40. Bayesteh H.; Sabermahani, M.: Field study on performance of jet grouting in low water content clay. Eng. Geol. 264, 105314 (2020)

41. Tadio, L.: Physical and mechanical characteristics of soilcrete: the influence of cement content and clay inclusions (2016)

42. Fang, Y.-S.; Liao, J.-J.; Lin, T.-K.: Mechanical properties of jet grouted soilcrete. Q. J. Eng. Geol. Hydrogeol. 27(3), 257-265 (1994)

43. Kriker, A.; Debicki, G.; Bali, A.; Khenfer, M.M.; Chabannet, M.: Mechanical properties of date palm fibres and concrete reinforced with date palm fibres in hot-dry climate. Cem. Concr. Compos. 27(5), 554-564 (2005) 
44. Zhao, Z.; Remond, S.; Damidot, D.; Xu, W.: Influence of hardened cement paste content on the water absorption of fine recycled concrete aggregates. J. Sustain. Cem. Mater. 2(3-4), 186-203 (2013)

45. Helson, O.; Beaucour, A.-L.; Eslami, J.; Noumowe, A.; Gotteland, P.: Physical and mechanical properties of soilcrete mixtures: Soil clay content and formulation parameters. Constr. Build. Mater. 131, 775-783 (2017)

46. Tajudin, S.A.A.; Mohammad Azmi, M.A.; Shahidan, S.; Abidin, M.H.Z.; Madun, A.: Relationship of physical parameters in $\mathrm{Pb}$ contaminated by stabilization/solidification method. MATEC Web Conf. 47 (2016). doi: https://doi.org/10.1051/matecconf/2016470 3015

47. Carașca, O.: Soil improvement by mixing: techniques and performances. Energy Procedia 85, 85-92 (2016)

48. Li, W.; O'Kelly, B.C.; Yang, M.; Fang, K.: Compressibility behaviour and properties of peaty soils from Dian-Chi Lake area, China. Eng. Geol. 277, 105778 (2020)

49. Sun, L.-Z.; Huang, Z.-P.: Dynamic void growth in rate-sensitive plastic solids. Int. J. Plast. 8(8), 903-924 (1992)

50. Consoli, N.C.; Rosa, D.A.; Cruz, R.C.; Dalla Rosa, A.: Water content, porosity and cement content as parameters controlling strength of artificially cemented silty soil. Eng. Geol. 122(3-4):328-333 (2011)
51. Chu, L.-M.; Yin, J.H.: Study on soil-cement grout interface shear strength of soil nailing by direct shear box testing method. Geomech. Geoengin. An Int. J. 1(4), 259-273 (2006)

52. Kolovos, K.G.; Asteris, P.G.; Cotsovos, D.M.; Badogiannis, E.; Tsivilis, S.: Mechanical properties of soilcrete mixtures modified with metakaolin. Constr. Build. Mater. 47, 1026-1036 (2013)

53. Shen, S.-L.; Wang, Z.-F.; Horpibulsuk, S.; Kim, Y.-H.: Jet grouting with a newly developed technology: the twin-jet method. Eng. Geol. 152(1), 87-95 (2013)

54. Mass, D. : Standard test method for laboratory determination of the fiber content of peat. Methods 04, 4-5, (2001). Doi: https://doi. org/10.1520/D1997-13.2. June 1991

55. ASTM D2976: Standard test method for $\mathrm{pH}$ of peat materials. ASTM Int. 71, 1-2 (2015). Doi: https://doi.org/10.1520/D297671R04.2. 